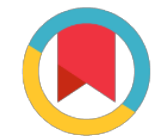

Check for updates
*For correspondence:

bxtruong1968@yahoo.com

Competing interests: The authors declare that no competing interests exist.

Received: 2017-04-28

Accepted: 2017-05-30

Published: 2017-09-05

Copyright The Author(s) 2017. This article is published with open access by BioMedPress (BMP).

This article is distributed under the terms of the Creative Commons Attribution License (CC-BY 4.0) which permits any use, distribution, and reproduction in any medium, provided the original author(s) and the source are credited.

\section{Helicobacter pylori infection in relation to pre-cancerous lesions in gastritis Vietnamese}

\author{
Trường Bùi Xuân, Nguyễn Thị -Thu Hiên
}

Department of Gastroenterology - Hepatology and GI Endoscopy, Vinmec International Hospital

Gastric cancer is one of the leading cancer lesions in Vietnam. Up to now, Helicobacter pylori (H. pylori) infection is still remaining a major pathogenic factor in patients with peptic disorders in Vietnam. Aims: The aim of the study was evaluated the correlation between $\mathrm{H}$. pylori infection with atrophic gastritis (AG), intestinal metaplasia (IM) and dysplasia (DP) in gastritis Vietnamese. Patients and Methods: A total of 161 gastritis patients including 105 males and 56 females with mean of age of $49.81 \pm 11.32$ years (21 - 79 years) were enrolled in the study. Upper Gl endoscopy was evaluated in all patients and afterward gastric biopsy specimens were taken according to the recommendation of update Sydney system and modified Baylor. The gastric biopsy specimens were analyzed with skilled pathologist who did not know about clinicoendoscopic status. The confirmation of $\mathrm{H}$. pylori infection was evaluated with urease test (clo-test) and Giemsa staining. Results: Of the 161 patients, 96 (59.6\%) patients were infected with $\mathrm{H}$. pylori, and about $72.05 \%(116 / 161)$ of patients was suffered from atrophic gastritis. The prevalence of atrophic gastritis in $\mathrm{H}$. pylori infected patients $(83 / 96,86.45 \%)$ was significantly higher than that in non-infected patients $(33 / 65$, $50.76 \%), p=0.041$. In the study, the prevalence of intestinal metaplasia and dysplasia was $84 / 161(52.17 \%)$ and $17 / 161(10.55 \%)$, respectively. The prevalence of intestinal metaplasia in $\mathrm{H}$. pylori infected patients was observed significantly higher than that in non-infected patients $(61 / 96,63.54 \%$ vs. $23 / 65,35.38 \%, p=0.044)$; and the prevalence of dysplasia in $\mathrm{H}$. pylori infected patients was also higher than that in non-infected patients $(14 / 96,14.58 \%$ vs. $3 / 65,4.61 \%, p=0.073)$. Conclusion: In gastritis Vietnamese, H. pylori was related to atrophic gastritis, intestinal metaplasia and dysplasia, so gastritis Vietnamese infected with $\mathrm{H}$. pylori could be categorized into high risk group for screening gastric cancer.

\title{
Keywords
}

H. pylori, Gastritis, Vietnam

Funding

References 